\title{
Teaching Skills through Literature
}

\author{
Saleh Ahmed Saif Abdulmughni \\ Prince Sattam Bin Abdul-Aziz University, KSA \\ E-mail: ashrafiafroz@gmail.com
}

Received: 22-08-2015

Published: 01-03-2016
Accepted: 15-11-2015

doi:10.7575/aiac.ijalel.v.5n.2p.10
Advance Access Published: December 2015

URL: http://dx.doi.org/10.7575/aiac.ijalel.v.5n.2p.10

\begin{abstract}
This study tries to investigate the contributory factors in the success and failure in teaching of the four language skills through teaching of literature because literature is critically and crucially relevant to the evolution of a literary sensibility. The basic end of literature is to read which develops reading skills and to reinterpret the dynamics of a given society. In this process the language skills are actually manifested. Literature, if we deconstruct the term involves two stages of reading; one that is the text, and second; the subsequent evaluation which entails the ability to break the text and trace the possibilities of meanings. This cannot be done without a proper perspective of the literary and linguistic mind, and the very act of interpretation amply appropriates reading skills. Literature fundamentally helps to develop the spirit of inquiry and the variety of thoughts involved in the representation of the text and; therefore, the study of literature enhances the ability to think beyond what you have been provided with and also to be equipped with a quizzical bent of mind that seeks to establish the competence to question what is read as a matter of literary text. This makes the learner naturally acquire the language from the literary context and consequently develop the language skills.

Teaching of language through literature has been a tested method as literary texts are so complete with vocabulary, the terrain of thoughts, the diversity of human encounters and the complexity of experiences. In the process of deconstructing a text, one comes across umpteen shades of thoughts conceived and delivered in a compressed form. Also the decoding of the language given its symbolic structure greatly enhances the prospects of independent thinking and writing. In this way the written skills are widely developed. A text is a bundle of thoughts clad in a complicated web of linguistic sophistication, and the sophistry alone suffices to constitute a challenge to break through the cordon of words that are generally ambiguous that provides an appropriate exposure to the complex patterns of language. Literature entails both the ambiguity of thoughts and the diversity of linguistic representations and therefore it is pertinent to stick to the teaching of literature as a means of decoding the language. It raises the range of vocabulary and the canvass of thoughts. If a novel is picked up for evaluation, the first task is the evaluation of the time background to suggest the socio-political tendencies, the words which are not commonly used, and the thoughts that are dressed in a highly complex form call for a more detailed engagement with the text. This is the best and perhaps the most effective way to develop the vocabulary, phrases, the stock of words, complex structures and the pieces of information compressed in a symbolic form. A novel is a document of thought expressed at a particular period and the language used can be extremely useful for the communication purposes even though they are words by the highly trained and proficient minds. However no literature can ever be seen in isolation from the language as 'language is culture'. Without a judicious selection of text the learner will be at a loss to understand the conflicting usage of language for the meaning of the word is not determined by the word alone, rather it is the context which determines its meaning. What can aid a learner, further, is the quality of mind in finding a method to respond to the situation as the teacher has their own limitations, and it will be difficult for a teacher to explain without a moderate exposure to the language or literature.
\end{abstract}

Keywords: Fourfold skills, foreign language learners, literary text, academic institutions, language patterns, teaching program, difficulties, context of the study, contributory factors of success, novel, drama, and poetry

\section{Introduction}

Teaching has great meanings and implications established on a philosophical perception. It is an intellectual effort that is done by experts to respond to many specific questions related to the objective of teaching, learners' characteristics, the meaning of education: How does it take place? How should the teaching be and the teaching materials planned? What is the best method for teaching? What are the characteristics of a good learner? What are the characteristics of a good teacher? What are the characteristics of the scientific teaching materials? And what are the related contributory factors involved in the teaching and learning process that effectively yield fruitful outcome? How can the learning outcome be measured? Does the teaching and learning process begin from scratch i. e., the learner a tabular as on which the teacher writes whatever appropriate information he wants to fill? These are the main rubrics under which many factors, elements and features can be investigated in the learning and teaching process.

The objective of teaching is to produce learning which is defined as the change that occurs in the learners' behavior or stock of knowledge and experience as a result of involving and interacting in the process of learning in a program. The increase in the accumulative knowledge and information of a person will lead, no doubt, to a better understanding of the 
circumstances; and consequently, a better-decision-making based on the knowledge an individual possesses. Proper teaching involves an organized planning, relevant teaching materials, selecting, sequencing, forming, recasting, grading and directing experiences to achieve objectives and targets.

There are a variety of factors that contribute to the success or failure of the teaching and learning program i.e., the quality of the product of academic institution (academic auditing and accountability) among which are the method, the approaches and techniques implemented in teaching program, the economic situations of the involved factors, the status of English in the educational curriculum, the characteristics of learners, the teacher (relevance of his training, quality of his teaching, method applied in the teaching process and his competence in the discipline he/she is dealing with), teaching materials, learning culture, the cultural assumption underlying the methodology of language learning and many other factors such as well stated aims and objectives of teaching English as a foreign language, the practicality of the aims and objectives and the potentiality of achieving them. A well designed and described program will lead to a more constructive outcome. A very clear teaching plan from which the description emanates/emerges for the program or the course.

Hence, the question that is usually asked by decision makers, the National Commission for Academic Accreditation and Assessment, (NCAAA), in the Kingdom of Saudi Arabia (KSA) is whether a particular academic institution fulfilled the goal of running a particular program or not. In another words, "Has the Ministry of Education, which made English language as a compulsory subject for about six years during the journey of the study run by learners, and an academic institution which teaches English major for about four years, been able to achieve their aims and objectives? If not, why? The institution or educationists should pin point the difficulties and hindrances that come between their goals and achieving them. This is because teaching and learning are similar to a factory owner who invest in a specific product and expect benefits. Similarly, decision makers invest in producing a particular product / learners with a particular quality to be able to compete with a product of other institution. Teaching-and-learning, in this sense, is reduced to a quantifiable category ultimately reduced to sums of money which equals to a quantity of knowledge.

\section{Rationale}

The aim of this cogency is not the argument for or against a particular teaching method, or approach, or praising the merits and depreciating the demerits of a particular theory at the cost of the other since the question raised is which is the best method for teaching the answer of which is in which cultural context and what are the characteristics of the learner and the teacher. So, if this is the case, the question of successful method is of no value for the language teaching method approach and techniques since they are based on some underlying cultural hypothesis; the learning culture, the financial conditions and social structure of the teaching venue or location of teaching, the number of learners in a class. This teaching/learning culture is a result of specific culture under unique circumstances; and consequently, differ from context to context, situation to another. Therefore, the generalization about the utility of a particular method in different cultural and pedagogical contexts does not ultimately produces the same outcome; and subsequently, the universalization of an experience or a method on global education with different variables and specialization might be a complete failure. Undoubtedly, learners should not be patterned like a machine product on which the certain test could be applied equally well on all the items. Hence, no method would be able to ensure a readymade success in various learning/teaching situations. Neither would advocating and propagandizing certain methods, approaches or techniques as superior or inferior to one another. It has no value in isolation and is not the aim of pedagogical orientation because the validity or the reliability of a particular method must be correlated with or in consonance with all the potential variables that may interfere with the teaching / learning process.

A close analysis of the objectives, cultural milieu, the economic situation, factor of time for the institution and the participants, characteristics of teachers and learners, availability of teaching techniques and their potential applicability, teaching material and all other hindrances that may encounter the teachers and learners are mandatory for determining the method of teaching. The anticipation of the success or failure of a particular method without taking into consideration all the involved factors in the learning process leads to a complete failure of the academic discourse. The choice of methods, approaches and techniques must be left flexible for the learning process that involve many variables such as learners, teachers, teaching materials and milieu. Among these factors learners are the soul or the center round whom the learning process rotates. For some predigests the best method is the one that has a philosophical consonance with the philosophy of an academic institution. The teacher should choose his method that coheres with the vision, mission, objectives and philosophy of an academic institution. The teacher cannot impose his personal opinions by totally ignoring the objectives of a particular academic institution. This does not mean that a teacher does not have a role in the choice of a particular method. A teacher should keep on changing his methods, approaches and techniques according to the situation. At the same time, a teacher should create consanguinity between the method, or methods that are chosen by him and the philosophy of an academic institution.

Spolsky (1989), Straveus (1977), Prabhu (1991) and Ellis (1985) stated that the learner is the focus of the teachinglearning process. The teachers' teaching materials and the teaching methodology are extraneous factors. They merely present a heavy input, but the learning or intake is naturally determined by factors related to the learner's internal learning mechanism, their other characteristics and situation. In addition to the above stated factors, the learners consciously or unconsciously are influenced by their learning experiences, their aptitudes and attitudes towards the target language. This very fact is determined by the general consensus towards the community of the target language and their culture. aThe received culture could be hostile, amicable, transcend, fraternal, copious or shallow, transient or established. The agreed universal notion towards its people and all the word nation's destiny/fate determinative casesor 
their understanding of the language learning are equally significant. The anticipated rewards of studying, their intrinsic or extrinsic motivation are all determinative factors in the process of learning and teaching. Other interfering factors that are used as a means of achieving a specific transient aim or such as meritorious requirement for a job, a vital element hindering his aspiration, access to culture of the target language in order to make stand against it. There could be intrinsic motivation such as conveying his correct thoughts, stands, cultural views and tenets to correct probable misunderstanding and eradicate any prejudiced erroneous notion. The integrative purpose is also taken into account. A learner may want to be an integral part of that society in order to avoid prejudices toward him or to get his rights. The learning style and strategies which might be wrong, tiring or time consuming etc are also important factors. (Prabhu,1991, Elilis,1985, Stravens, 1977, and Spolsky 1989). These are the factors at the back of the learners' consciousness when he comes to a class (Bassano, 1986; Davies et al 1994). The harmony of these factors with the learner's underlying assumptions towards them along with his other characteristics previously mentioned might be construed as a sound achievement. But in case of, (Claxton1968, and Murrel, 1987, Basano, 1986; Divies etal, 1994). Hence, the harmonious relation among these elements with the method of teaching is vital for the success of language learning process. Conversely, the antagonistic nature in their relation, no doubt, threatens the learning process. Claxton and Ralston, (1978), Claxton and Murrel, (1987).

At this point of discussion, shall we surrender to the aforementioned facts that there is nothing that could be done about the characteristics of the learners? A teacher, always, can change some of the characteristics of the learner. He can motivate the leaner by different means. A teacher can encourage the learner by highly praising him when he responds correctly to a question or does exercises, or understands the meaning of some word. A teacher can contribute to the different types of learner's intrinsic or extrinsic motivation by stating the importance of learning a language, or the kind of reward a learner may be given as a result of successfully completing a learning program. A teacher can make the learner love the learning of a language. He should eradicate the cultural erroneous notions toward the culture of a target language. He should demonstrate the positive aspects in the culture of the target language in order to minimize the cultural clash between the learners' mother tongue and the target language. One very important thing in the mind of the learners should be changed. Many students come to the class with the idea that language is very difficult to learn. This notion may have been created by some other learners who had bad experiences in learning the language. If a leaner believes that language is difficult, there is no way you can teach him. This belief is the first step toward failure. A teacher, first of all, eradicates this notion from the mind of a learner. For example, what I used to do to dispel this misconception from the learners' mind is that I teach them three patterns: Subject + Verb to be + one of the complements (noun/adjective/adverb): He is Ahmed/good/out. Then, I say that if you know this rule, it means that you understand a quarter of the rules of a language because there are only eight declarative sentences in the whole English language.

On equal footing of importance is to choose the ability of topics and linguistic content of the course which must be approximate to the learner's functional needs that spread all over the repertoire of a language i.e., between highly specific purpose (ESP) and very general purpose (EGP) since the language learner may not be able to foresee his need in anything but for the most general terms. However, importance must be given on the basis of relative frequency, neutrality of language and some particular form of occurrence in a particular situation. In this respect, a learner must be empowered with vocabulary that enables him to competently describe his location, movements in the location, institutions and their functions, their different activities in commercial transactions, banking, contracting, written and spoken correspondence, different transportations that guarantee the consolidation of the common core at the beginning, and then, gradually acquainted with all structures.

A thorough exposure to the usage of a word in different contexts and its potential use as a different part of speech is highly important in language acquisition. Similarly, the focus on the limitation of the expressivity of the sense of the word in different context should be highlighted providing all the words that could be alternatively used to express the same action in different contexts. This can be achieved by a thorough and comprehensive exercises and teaching material. The following example will explicate the point, for example the Arabic verb/ nazala / نز $\mathrm{j}$ has a value currency in all contexts expressing action of something / a body moves from a higher position to a lower one. This is because of the possibility of deriving many different forms of the same verb. Its counterparts English are as many as forty different words or more depending on different situations a few of which are as follows: got down, came down, stepped down, alighted, sank, inhibit, etc. So lexical grouping that expresses the same sense in different situations, contexts, and discourse with enough examples that guarantee the illumination of the different meanings and shades of meanings.

There are some basic assumptions for beginners of any language because language learning is basically helping the learner to get a reasonably good command over the important language skills that have not covered all the linguistic repertoire of the functions of the mother tongue. Learning English as a foreign language does not necessitate learning the entire repertoire of the functions of the mother tongue. Of course, the main purpose of any language is to carry on successful communication tasks at different official contacts and interactions and, to some extents, social communication. These communications and interactions may be at several levels of sophistications, general or specialized topics. Different learners have different needs for studying a language or even any field. The main objective for learning a language depends on the different functions that a learner is expected to play and involve in and the reason for learning a language. For example, the need of someone who learns language for accessing his thought and ideas at a bus station or restaurant or travel agency is different from the needs of someone who wants to involve in a serious sophisticated interaction such as serious cultural political talk. So the main objective of learning a language depends on the reason for studying a language. Concerning the reasons for studying English in the Middle Eastern: 
Kingdom of Saudi Arabia, Yemen, and the pan Arab world fluctuate from getting mastery over some very structures and linguistic patterns to use them in specific or particular situations, such as finding the way to specific place, ordering some food in a restaurant, booking a ticket or a room in a hotel to a very sophisticated intellectual talk and activity such as a political debate, a scientific conference, studying a very advanced discipline, negotiation over a specific issue or explaining a particular stand toward a particular issue. In other words, we need English for simple conversation to a highly sophisticated decoding and encoding process whether in written text or spoken code. The characteristics of the outcome product of the Department of English must be highly qualified to involve in very sophisticated arguments if not productively at least receptively. The aims and objectives of the Department of English is not to produce someone who is only capable of writing some English sentences in specific issue or hardly able to communicate effectively in different situations or cannot understand a written literary or general texts of advanced level. If the end product of a Department of English cannot express himself very effectively in writing or spoken form, or reading and comprehending different types of texts, or translating at least into Arabic, an institution is merely wasting its time. Really some products of some Departments of English are less capable than the out product of a very primitive institute which offers English courses for US 100 dollars.

The aim of any department of English is to teach the fourfold skills proficiently, effectively, in general, English and specific English because the learner is exposed to many varieties of English prescribed in the curriculum. Therefore, it is assumed that a learner learns the skills that are a matter of practice as well as the learning about the language, civilization, culture and literature. For the English major, a learner, first of all, has to acquire the four skills: reading, writing, speaking and listening skills and the sciences about language and literature during the period of acquiring these skills. All these languages and literary sciences and skills that are taught to the learner are amalgamated and integrated altogether into a whole because all the skills overlap each other into one integrated skill. This becomes very obvious because when we talk we use all the four skills at the same time.

The common factor involved in all these skills is the language code and it is a common knowledge that language means spoken language i.e., language is speaking and listening skills. Writing and reading are secondary. They are graphic representations of the spoken language. In the past, there was not even written language. Even today, there are some languages without (script) writing systems. Hence, learning a language is the learning to speak. The implication is that listening and speaking are the two language skills, and the writing and reading are the learning of its graphology. Robert Lado (1980) rightly says that learning to speak and understand means learning the language, whereas reading and writing imply that the language is known, and that we are learning a graphic representation of it. The ability of using a language means the ability of communicating effectively. However, at this point in time of the historical development of human race, the concept of learning a language necessarily entails the learning of writing and reading skills because these two skills became a means of speaking and listening. These fourfold skills are integratively taught. As previously argued there are a variety of factors that contribute to the success or failure of the teaching and learning program among which is the teaching materials. Language teaching is logically presented in text and in particular context. The ritual practice followed by departments of English in the entire Arab world is that the teaching material of the English major is divided into three separate divisions, namely, the four skills teaching materials, the linguistics and literature courses each of which is taught independently. There is no harm in this approach as far as the assumption is that the locus of learning, where the interaction and merging of these three entities, is the unifying force of these three facets of the same currency from which a unifying integrated whole/learning would emerge. And this is how generations of learners had been learning a language and its sciences and literature. However, from period to period, the attitudes, opinion, approaches, and techniques of teaching and the quality of learners are changing. Language learners used to exert very great efforts to study language. Their teacher was the only informant of learning. Learners depended on him to give the meaning of words, phrases, correctness of patterns, pronunciation. Nowadays, pronunciation of words is accessible to all learners in all types of electronic communications, and translations are in their cell phones. As a result, they do not exert effort like they didin the past because life diverged and attentions deviated to many complications of the age such as Internet. In addition, there were many communication networks and many other worries and anxieties that divert learners' attention and concentrations. Accordingly, the teaching materials have to be properly organized, planned and utilized, and instead of teaching literature as a separate domain the aim of which is to teach only literary information such as plot, theme, characterizations, literary terms etc., one can use a literary text to teach the fourfold skills. There is no better teaching material than a literary text to teach the skills. No doubt, the core of most teaching of English is text. It is used as a teaching device. Unfortunately, the general trends do utilize a literary text for teaching the language skills. Although teaching literary information is mandatory, it would be more appropriate and beneficial for teaching the literary genre as well as the skills. This is because if the literary text is used as a language skill text, the learners and teachers will study it thoroughly and will be forced to go back to it repetitively. In this way the literary information would be better understood and memorized and the language skills would better be learnt and enforced. The whole enterprise of teaching should result in the developing of the language skills. This is what I do even when teaching grammar, applied linguistics, language acquisition, TGG, language and society, I try to take care of reading, writing, listening and speaking skills. For example, I ensure that learners listen to me attentively while explaining a linguistic issue, and then I ask questions to elicitresponses. After that, I instruct the learners to read the text and ask the questions about it. A collective discussion about the ideas in the text is ensued. Moreover, I pinpoint some complex structure and analyze the internal relationship of the element, specially, those meaning of which cannot be understood as a result of the complexity of the structure of the phrase and clauses. Finally, learners are asked to write the answers of some questions. In this way, I end up teaching the fourfold skill and properly teachthe linguistic information which is very 
necessary for the learners of a language. Poetry as sheer sound has always been fascinating for the poets and their readers of poetry is language which has been organized and chosen with great care.In some ways it represents the most skilful use of language. Sounds patterns play a very crucial role in poetry, and poetry being mainly an oral art form, its true effect comes from being read or recited loudly. Hopkins was a poet who exploited sound for its own sake; he was interested in problems of meters, rhyme, assonance and alliteration which arise when one regards a poem as a pattern of sound as well as a structure of meaning and imagery. Besides these recordings of famous plays, speeches and poetry can be heard in class to develop the listening and comprehension skills. McIntosh, Strevens, Haliday are of the view that "no student is to be pushed into literary work until he has sufficient linguistic ability to understand, enjoy and appreciate the literary texts that he will be studying." Linguistic Science and Language Teaching (sec-2). In short, all the skills can be taught interactively when teaching any literary genre. Some pieces of written work are intricate in nature and require close reading of the text. Difficult poems and novels require such intensive repeated reading with great concentration. To ensure that the students are reading the work, short questions should be asked after a specific time. A learner should be allowed to tackle the literary text independently and the teacher can provide help whenever needed. Of course a literary text represents a problem for a learner to comprehend .This is because of the long tail of phrases and clauses that are structured together in a sentence. It becomes very difficult for a learner to specify the main elements of the sentence that is the subject, verb and complement. It becomes confusing for even an advanced learner to distinguish the main element from the subordinate elements in the sentence. These difficulties impair the understanding of a text. The teacher should play a very important role in facilitating the content of a text for the learners. Sometimes, it becomes difficult for the learner to understand the meaning of a literary or even ordinary text. This is because of the structure of a text. There could be two or more subordinate clauses and a long tail of pre-modifiers and post modifiers of the internal structures of the main elements/heads of the phrases and clauses. Consequently, it becomes difficult for the learner to understand the message .He mistakes the main message with the subordinate one. More precisely the learner mistakes the noun phrase/subject of the subordinate clause for noun phrase/ subject of the main clause and the vice versa is true. So, literary teachers, most of the time, should take recourse to the sentence analysis to show the interrelationship of the elements of the sentence to show how the sentence was constructed. This is because the literary texts are different from non-literary texts in many ways at the top of which are the parallelism or deviation from the normal non-literary text . This makes the literary text difficult to understand for the learner. Therefore, linguistic analysis of the text is very necessary for the learner to understand the content. This example is given in order to make the idea clear. In the following sentence, there are many phrases, subjects, objects, complements and many clauses as can be seen:

In a highly attended civilian court the size of the Faculty of Arts and Science in Wadi Ad-Dawasir where he used to be present with his enemy, he displayed an outrageous pimpled cheek toward the jury when they started to interrogate him about the incident.

The learners' memories find it very taxing to remember this sentence from the beginning to the end because the memory of non-native speaker becomes weak in the second language learning. Again, it is not easy for the learners to pinpoint the element of the main clause. Sometimes we find that some learners do not know how to understand the meaning in a sentence especially when they translate because they were not trained to do so. Learners must be taught how to read the sentences in order to decipher the meaning. For example, a learner should be taught to read the above sentence as follows:

$$
\text { He displayed }(. . . \text {..........) cheeks ..where......to whom.... Why...... }
$$

At least a teacher should recast the sentence like this in order to make it easier for a learner to understand. He also should tell the learner about the usual order of the sentence elements and why the speaker changed the order.

At advanced level if the teacher has enough time he should go on analyzing the internal elements of a sentence. Some literary teachers do not know the technical analysis of the sentence. It is enough to tell the learner who did the action/the subject, what the action/the verb is, who or what received the action/the object, the location of the subject/adverb of place and the time of the action/adverb of time, the way of performing the action/adverb of manner. Many people would say that they are fluent speakers of English, but they do not know these technical terms. I would argue that a literature teacher should be able to tell the learner who, did what, to whom, where, when and how. These are crucial for the learner to understand the complex sentences.

A canonical work of English literature can be taught for a literary merit and used to create sufficient linguistic ability. It is quite possible to use literature to teach language, and teaching language means imparting the four skills. It is quite possible to use literature to teach language/the four skills as I exemplified above. When I teach linguistic subjects, I exploit the linguistic texts for teaching the four skills. I do not teach only about a language but also the language skills. Literature teaching would be more appropriate through which you can teach language skills, vocabulary, grammar, semantics, stylistics, and pragmatics.

Whether a teacher teaches plays, novels, poetry, stories, he/she can teach reading by asking his/her learners to read loudly and silently in small groups or large groups and the rest of the learners listen. This can be followed by discussing the ideas undertaken by the writer or the speaker in the text. Then, any writing task is to be prescribed for the learners to do at home whether it was a summary of the ideas, the learners' response to what he is reading, or answering some questions. This is how the four skills can be taught interactively.

Reading means reading comprehension i.e., reading fast and grasping what is being read. Extensive reading of a written literary text provides sustained rapid self-directed activity. Students should be encouraged to read works other 
than the prescribed text or at least they should read the prescribed ones. Some prefer to instruct the learner to read other poems, novels and plays. However, I instruct the beginners and intermediate levels to read every text several times so that the linguistic patterns become familiar on the bases of which the learner will be able to produce similar patterns. Reading a text repetitively represents a kind of pattern practice and a means of memorization of words. At advanced level, learners are instructed to read texts other than the prescribed ones in order to understand the style of the same writer, enrich his vocabulary, and increase his fluency.

Drama which is the description of event from real life is the most appropriate to teach speaking skills. It is a recreation of real life dialogue. It utilizes all of the communication skills. Moreover, the language in the play is the spoken language.

Halliday rightly says, "Literature is language for its own sake: the only use of language perhaps where the aim is to use language." Literature exhibits only the organizational aspects of the four skills. This aspect is concerned with the organizing of the units of the language into acceptable patterns as well as with the ability to discern and analyze such patterns when read or heard.

One of the meanings of teaching a language is the acquisition of good linguistic habits, and accordingly, literature can be very appropriate for teaching these habits because it is the storehouse religious practice, rituals, mores, conventions, traditions, habits, folkways, arts, inventions, creativities of a society and culture. There is strong and inseparable bond among culture, literature and language. So, the best teaching of language is the literature which is the house of the culture through which the language can be developed. In other words, it is imperative to make language learners a good readers, speakers, writers and listeners. These are all can be exploited while teaching literary text as demonstrated in the above argument.

\section{Conclusion}

Literature is critically and crucially relevant to the teaching of the four skills. Since the aim of literature is enjoyment, enlightenment, crux of the gain/sap of human experience it would itself motivate the learner to read with enjoyments, entertainment, obsession, and passion. Consequently, the acquisition of language and the fourfold skills will naturally and spontaneously take place. Teaching of literature if properly done with a view to developing the language and the four skills and not only restricted to the demonstration of the literary artifacts such as theme, plot, characterization, etc., would really enhance the speed of the language learning process and skills. This is because a literary text is a bundle of thoughts clad in a complicated web of linguistic sophistication., The sophistry of a literary alone suffices to constitute a challenge for the reader to break through the cordon of words that are generally ambiguous and avail himself an appropriate exposure to the complex patterns of language. Literature entails both the ambiguity of thoughts and the diversity of linguistic representations and, therefore, it is pertinent to stick to the teaching of literature as a means of decoding the language. It raises the range of vocabulary and the canvass of thoughts. Literary texts present the diversity of linguistic representation which cannot be found in any non-literary text.

Teaching of language through literature has been a tested method, as literary texts are so replete with vocabulary, the terrain of thoughts, the diversity of human encounters and the complexity of experiences. Also the decoding of the language, given its symbolic structure, greatly enhances the prospects of independent thinking and writing. Literary text provides the best opportunity for creative thought. The thoughts that are dressed in a highly complex form call for a more detailed engagements with the texts. This is the best and perhaps the most effective way to develop the vocabulary, phrases, the stock of words, complex structures and the pieces of information compressed in a symbolic form.

The language used in a literary text can be extremely useful for the communication purposes even though they are words by the highly trained and proficient minds. No literature can ever be seen in isolation from the language, as language is culture. It understands the conflicting usage of language for the meaning of the word is not determined by the word alone, rather it is the context which determines its meaning. What can aid a learner, further, is the quality of mind in finding a method to respond to the situation as the teacher has their own limitations, and it will be difficult for a teacher to explain without a moderate exposure to the language or literature.

In order to guarantee a qualitative outcome, a variety of factors that contribute to the success or failure of the teaching and learning program should be controlled and monitored among which are the method, the approaches and techniques implemented in teaching program, the economic situations of the involved factors, the status of English in the educational curriculum, the characteristics of learners, the teacher (relevance of his training, quality of his teaching, method implemented in the teaching process and his competence in the discipline one is dealing with), teaching materials, learning culture, the cultural assumption underlying the methodology of language learning and many other factors such as: well stated aims and objectives of teaching English as a foreign language, the practicality of the aims and objectives and the potentiality of achieving them. A well designed and described program will lead to a more constructive outcome.

\section{References}

Ellis, R. (1981). The role of input in language acquisition: some implications for second language learning. Applied Linguistics, 2(1), 60-87. 
Bialy stock, E. and Frohlich, M. (1980). Oral communication strategies for lexical difficulties. Interlanguage Studies Bulletin (Utrecht) 5(1), 3-29.

Brown, H. D. (1980). Principles of language learning and teaching. New Jersey: Prentice Hall

Brown, H. D. (1981). Affective factors in second language learning. The second language classroom: Directions for the eighties, 111-129.

Burstall, C. (1975). Factors affecting foreign language learning: a consideration of some recent findings'. Language Teaching and Linguistics: Abstracts vol.8, no.1, pp.5-25Reprinted in Kinsella, 1978.

Burt, M., \& Dulay, H. (1980). Optimal language learning environments. The Second Language Classroom: Directions for the, 175-192.

Carrol. J. B. (1981). Conscious and automatic processes in language learning. Canadian Modern Language Review, 37(3), $462-74$.

Chapman, R. (1973). Linguistics and Literature, Edward Arnold.

Turner, G.W. (1973). Stylistics, Penguin Books, UK.

Ellis, Rod. (1985). Understanding second language acquisition, oxford university Press.

Fowler, R. (1971). The Language of Literature, Routledge \& Kegan Paul.

Leech, G. N. and Shot, M. H. (1981). Style in fiction: A linguistic introduction to English fictional prose.

Halliday, M. A. K., Mcintosh, A., and Strevens, P. (1964). The Linguistic Sciences and Language Teaching .London: Longmans.

Halliday, M. A. K.,(1971), Linguistic function and literary style, in:' Exploration in the Function of Language' London, Edward ARnold,103-38.

Spolsky, B. (1989). Conditions for second language learning: Introduction to general theory, Oxford University Press.

Widdowson, H. G. (1975). Longman Group T. \& A . Constable Ltd, Edinburgh, UK.

Lado, R. (1980). Linguistics Across Cultures: Applied Linguistics for Language Teachers. 